\title{
A Brief Discussion on the Current Situation and Problems of the Protection of Tibet's Historic Buildings
}

\author{
Yuan Gao \\ Xizang Minzu University, Xianyang, China \\ Email:gaoyuan@163.com
}

How to cite this paper: Gao, Y. (2018) A Brief Discussion on the Current Situation and Problems of the Protection of Tibet's Historic Buildings. Open Journal of Social Sciences, 6, 48-53. https://doi.org/10.4236/jss.2018.64005

Received: March 12, 2018

Accepted: April 15, 2018

Published: April 20, 2018

Copyright $\odot 2018$ by author and Scientific Research Publishing Inc. This work is licensed under the Creative Commons Attribution International License (CC BY 4.0).

http://creativecommons.org/licenses/by/4.0/

\begin{abstract}
The protection of historic buildings is one of the important tasks to promote the development of modern civilization, which is also of great significance to the development of contemporary architecture. All countries in the world attach great importance to the protection of historic buildings. There are still many problems in the protection of historic buildings in China, and it needs further improvement. This paper takes the historical and cultural district of Jiangzi city in the southwest of Tibet autonomous region as an example, analyzes the present situation and problems of historic building protection in China and gives some suggestions.
\end{abstract}

\section{Keywords}

Historic Buildings, Protection, Development

\section{Introduction}

Historic buildings are unique, rare or historic buildings which have significant impact on architectural art, literary sculpture, landscape and landscape design and development of human settlements in a certain period of time or in a certain cultural area of the world. It represents the commemoration and pursuit of the past, appreciation and inheritance of lost culture. It has irreplaceable value and function in modern civilization [1].

Located in the southwest of the Tibet autonomous region, Jiangzi city has a rich cultural heritage. Jiangzi city is the third largest city in the history of Tibet. However, due to the lack of ability and motivation of block protection and self-renewal, the local government had to adopt a static "mothballed" protection strategy. Due to the backward social and economic development, the lack of in- 
frastructure and the deteriorating living environment, some residents are forced to leave. The historical environment and traditional cultural heritage are fading away with the diminishing of residents' life.

This paper discusses the implementation means of protection and renovation of block buildings and puts forward some viewpoints and methods on the basis of deeply analyzing the background of Tibetan social development and cultural heritage protection, and of the social and cultural situation of Jiangzi historical and cultural district.

\section{The Former and Current Situations of Tibet's Historic Buildings}

Mentioning Tibet, many people think of the grand Potala palace, many lama temples and strange and unique customs and cultures. But after this, they think most of poor and backwards. With the strong influence of religious factors on Tibetan social life for a long time, closed geography situation, harsh climate, fragile ecological environment, Tibet has a strong religious atmosphere, the social development is slow and the living standards of people is low. But it is in this natural historical context that the Tibetan people have created a unique and diverse national culture on this snowy plateau [2].

The average elevation of Jiangzi city is above 4050 meters. Jiangzi is called "JieKaErZi" in Tibetan language. The meaning of the name is supreme palace. It is the third largest city in Tibetan history, which have some important cultural heritage resources such as Baiju temple, Para manor and Zongshan castle. In 1994, Jiangzi was named the third batch of famous historical and cultural cities in China by the state council. In 2014, it was rated as China's most beautiful town, which is the only city in Tibet on the list. In the year of 1904, the British imperialists invaded Tibet. The people of Jiangzi revolted against the armed aggression of the British imperialists. From that time, Jiangzi has been known as the "Hero City". In the 1930s, the famous Italian scholar Tucci who studied the Tibetan culture had done a lot of research in the ancient city of Jiangzi, and he was famous for his book series named Brahmaputra. It has a detailed description of the architecture and murals of Jiangzi city.

Since the peaceful liberation of Tibet in 1951, especially after the democratic reforms of 1959, the former serfdom society has undergone tremendous changes in economy, culture, science and technology. Due to the extremely poor natural conditions, Tibet's social and economic development is still backward. After the reform and opening up policy, the central government has held four meetings in Tibet since 1980, doing special study on the economic and social development of Tibet. In 1994, the central government was at the third Tibet work conference, which made the important decisions of concerning Tibet and all parts of the country supporting Tibet. A series of special preferential policies and measures to accelerate the development of Tibet were formulated. Thus, the state has formed a comprehensive framework of supporting Tibet's modernization in 
which the state directly invests in Tibet construction projects, the central government implements financial subsidies and all provinces and cities across the country support Tibet. This industrial structure has not produced good industrial production value, instead, it has brought serious environmental pressure. Restricted to a fragile ecological environment, the irrational industrial structure characterized by the "economy to survive" has no ability to accumulate capital. The farmers and herdsmen in Tibet still lack effective ways to increase their income.

Apart from the insufficient economic capacity, Tibet depends on central financial and material subsidies for a long term. Tibet's economic and social development also faces a series of other difficulties. In a very long time, Tibet had formed a typical resource-intensive industrial structure, because it was affected by the traditional pattern of industrial development.

At present, more and more scholars pay their attention to the ancient city of Jiangzi and Tibetan architecture. From the year of 2008 to 2010, Hou Weidong, the former secretary of the Chinese academy of cultural heritage, traveled across the Jiangzi city. He surveyed the ancient buildings in Jiangzi. He talked about the comprehensive considerations of the Tibetan architecture due to its particular characteristics. He said," The culture and religion in Tibet are special. We need to think about its needs in a comprehensive way. The first requirement for cultural relics is their reality. The so-called reality includes its history, and its original structural materials. We also should consider the needs of religious groups. So, these new and old relationships deserve our constant discussions."

In the 21st century, the development is the top issue. All places are looking for their better and faster developments. And the development of Tibet is facing more serious problems than the development of the mainland. About 85 percent of the population of Tibet live in the farming and pastoral areas. Most of them are still in the stage of traditional farming and animal husbandry industry. The social economy of Tibet shows remarkable characteristic of "atypical duality", which has restricted Tibet's economic and social developments as a result.

In particular, some towns are built in the background of traditional farming and pastoral settlements. For example, the ancient city of Jiangzi, although it is also adjusted by the social, cultural, ethnic and policies of the socialist countries, however, it is still affected by the old ideology in the regional society in the system of social operation. It shows a wide range of religion and customs. In the economic structure, the development of modern industry in the ancient city of Jiangzi lags behind the development of the traditional industries. The modern and traditional industries are difficult to form parallel operations and mutual promotions, which results in economic poverty. Under the influence of this atypical dual binary structure, on one hand, the ancient city of Jiangzi has been regarded as the only traditional cultural carrier of old Tibet with its relatively complete traditional town style and traditional life style.

But on the other hand, it is a common phenomenon that the economic development in the ancient city of Jiangzi is backward, and its infrastructure is in- 
adequate, residential environment is deteriorating, and its blocks lack vitality.

The 21 st century is not the same as the past hundreds of years in which time the city had being closed to the outside world. Tibetan society is facing an unprecedented and inevitable modern transformation nowadays, and the modern civilization of the outside world constantly influence and tempt the place. The old culture of surprise, bewilderment and strangeness among travelers and explorers is undergoing tremendous changes. Some are slowly disappearing.

\section{The Main Problems in the Protection of Historic Buildings in Tibet}

\subsection{Outward Movement of Population}

The migration of the population is an important reason for the fading of historical features and vitality of the old city. The family movement appears to be an ordinary event, but in fact it is not. First of all, it means that the living conditions here have actually caused the inconvenience for people's life. Because people often don't easily give up a place where they live for generations and start a new adventure. Second, there is a strong possibility of a vicious circle between "relocation" and "decline". The outward movement resulted in the abandonments of the house and wasting resources. It also will directly cause the loss of traditional living atmosphere in the old town. Thus, the foundation of traditional culture is shaken [3].

\subsection{Lack of Infrastructure}

Infrastructure in Tibet is insufficient. For example, water is available only between 9 a.m. and 12 a.m., and only the old streets are set up to draw water points. The residents on the mountain have to rely on manpower to bring water on back and put the water in the tank for use, which has brought great inconvenience to life. Drainage is another major problem in the old city. Due to the lack of drainage pipes, all kinds of domestic sewage produced by each household are only along the small roadway between the houses and gathered in the ditch of the old street, which has brought great danger to the health of people.

\subsection{Block Protection Planning Lags Behind}

In addition, the government department protection planning is seriously lagging behind. It has not been possible to make reasonable arrangements for the overall protection of the old city. Instead, it takes a passive "mothball" protection method. Architectural renewal in the area of protection is basically banned. The only thing residents and governments, especially in villages and towns, can do now is to wait for the higher authorities to publish the block plan.

\section{Suggestions and Prospects for the Protection of Historic Buildings}

In recent years, scholars have discussed the future development mode of Tibetan 
economy and society. Under the guidance of the sustainable development concept, scholars believe that social development in Tibet should be given priority to the survival and development of farmers and herdsmen. We should attach importance to human development, raise the level of social development and explore ways of sustainable development [4].

The protection of historic buildings is a task that is related to the whole society and all mankind. To finish this task, we should start from the following aspects.

\subsection{Infrastructure Renovation and Housing Projects}

According to the urban infrastructure construction plan of the 11th five-year plan of Jiangze county and the plan for the protection of historical and cultural districts in Jiangzi county, Jiangzi historical and cultural district will invest in the transformation of water supply and drainage system, transformation of power communication system, urban greening and public facilities renovation. For example, the local governments carry out the daily environmental regulation and improve the environments there, and they also implement the rural network entry project. The improved infrastructure will make people's life there more convenient which will prevent people from moving outside to some extent.

\subsection{Policy of Community Tourism Development}

In recent years, with the opening of the Qinghai-Tibet railway, Tibet's tourism industry has developed greatly. The number of visitors to Tibet reached 4.02 million in the year of 2007 , with $\$ 4.8$ billion in revenue. That's 3.6, 3.8 times higher separately than those in the year of 2002, which consititutes 14 percent of Tibet's GDP. Jiangzi county benefited from rich historical and cultural resources, and in recent years its tourism development momentum is good. It still has great potential for tourism development. The development of tourism will provide more jobs to the local people, which can also prevent people from moving outside.

In order to cooperate with the development of tourism and increase the income of farmers and herdsmen. The government should improve the organization of farmers and herdsmen in rural tourism, guide farmers and herdsmen in non-agricultural industries such as tourism and special product processing industries to improve their ability to get rid of poverty. For example, Jiangzi county also carried out the construction of tourism demonstration sites for farmers and herdsmen. It combines the living experience of the farming and animal husbandry with the cultural heritage resources tourism, and it creates a platform for residents to participate in the development of tourism industry through invested appropriate funds.

\subsection{Skills Training for Farmers and Herdsmen}

In the work report of the government of the Tibet autonomous region in 2008, the government will allocate 50 million yuan to train 130,000 farmers and 
herdsmen with characteristic industrial skills. Government should actively cultivate farmers and herdsmen agents and energetically develop professional cooperative organizations for farmers and herdsmen. To improve the degree of community organization of farmers and herdsmen in the aspects of processing and sales, labor export and rural tourism. And in the process of training, the government, farmers and herdsmen, and the third party participating in training could select community advantage projects to determine the content of the training and the target and establish the long-term guiding mechanism on the basis of analyzing the advantages of the community.

\section{Conclusion}

The 21st century is not the same as the past hundreds of years when the city had been closed to the outside world. But these days Tibetan society is facing an unprecedented and inevitable modern transformation, and the modern civilization of the outside world constantly influences and tempts the place and the people. The old cultures and traditional architectures are undergoing some tremendous changes. Some are even slowly disappearing. So, the protection of Tibet's historic buildings is very important, just as the protection of historic buildings is very important to each country. It is helpful to promote the development of modern civilization and it contributes to the development of architectures. So, governments should carry out some effective measures to protect the historic buildings. This article provides some ways to protect the historic buildings, such as renovating infrastructures or carrying out some related policies. But governments should think out more ways and try to call the whole society to protect the historic buildings together.

\section{References}

[1] Ge, L. (2008) China Tibetology Research Center 20 Years-Academic Speech Record. China Tibetology Press, 1-11.

[2] Wang, Y.D. (2005) A Preliminary Exploration of Urban Space and Residential Building Type in Laocheng District of Lhasa. Nanjing University of Technology, $2-5$.

[3] Jiao, Y.X. and Liu, Y.T. (2008) Seeking the Integration of Historical Preservation and Community Development-Discussion on the Protection and Improvement of Community Development in Historical and Cultural District. Journal of Chongqing Jianzhu University, 30, 33-37.

[4] Zhao, M. and Zhao, W. (2003) Community Development Planning-Theory and Practice. China Building Industry Press, 28. 